\title{
South Africa as an information and knowledge society: the benefit to informal sector women entrepreneurs
}

\author{
Glenrose V. Jiyane ${ }^{1}$, Mabel K. Majanja ${ }^{2}$, Bertha J. Mostert ${ }^{3}$ and Dennis Ocholla ${ }^{4}$ \\ jiyangv@unisa.ac.za; majanmk@unisa.ac.za; bjmostert@unizulu.ac.za; ochollad@unizulu.ac.za
}

Received: 10 April 2013
Accepted 13 June 2013

The use of tools for development has evolved from the industrial revolution over time. The late $18^{\text {th }}$ and $19^{\text {th }}$ centuries saw the increased use of machines and developments in the mining industries; in the $20^{\text {th }}$ century, there was increased use of information and technology; and major breakthroughs sparked the evolution of the information and knowledge society of the $21^{\text {st }}$ century. The basis of the information and knowledge society revolves around technology's increased assimilation and diffusion in human society, particularly information and communication technologies and their rapid growth and use in the exchange of information and knowledge. This society offers many opportunities and benefits to people in terms of the facilitation of information creation, distribution, diffusion, access and use for growth and development in various spheres of life. In this paper we discuss the role of the information and knowledge society (IKS) for informal sector women entrepreneurs (ISWEs) and focus on what there is in the IKS that could benefit ISWES, analyse the criteria, indicators and benefits of IKS and explore the challenges and opportunities of IKS. At the end of the paper we provide recommendations for the development of IKS for the benefit of rural women. The paper is informed by recent doctoral work on the role of the information and knowledge society in poverty alleviation and the economic empowerment of women entrepreneurs in South Africa's informal sector. We find that by using criteria and indicators of an information and knowledge society to assess whether or not South Africa meets these requirements, South Africa indeed meets some of the criteria. However, it does not, in many instances, satisfy other criteria, and thus cannot be regarded unconditionally as an information and knowledge society. We recommend that South Africa should work toward achieving and meeting the criteria of the information and knowledge society by assessing itself against the criteria and indicators of such a society. Doing so would enable informal sector women entrepreneurs to reap the opportunities presented by the information and knowledge society.

Keywords: South Africa, information and knowledge society, informal sector women entrepreneurs

\section{Introduction}

An information society is a society that is organised around knowledge for social control and directing innovation and change (Bell 1974: 20). In 1988, Martin (1988:42) defined an information society as "a society in which the quality of life, as well as the prospects for social change and economic development, depends increasingly on information and its exploitation". The author stresses that in such a society, living standards, patterns of work and leisure, the education system and the market place, are all markedly influenced by advances in information and knowledge. According to Britz et al. (2006:27), in an information and knowledge society, knowledge has become the most important production factor. The authors explain that in this society, there is a culture of knowledge production that is underpinned by a higher level of education with a focus not only on the use of modern information and communication technologies (ICTs), but also on content.

According to Abid (2002:1), the importance of information and knowledge lies not only in the principal forces of social transformation, but also in the promise that many of the problems confronting human societies could be significantly alleviated if only the requisite information and expertise were systematically employed and shared. Significantly, Nassimbeni (1998) notes that very few operational definitions of the concept "information and knowledge society" exist, making it difficult to decide whether or not a country or community has moved forward in its quest to achieve this status. According to Lor and Britz (2007:392), many authors use the concept ",information society" interchangeably with the newer concept of the knowledge society. However, the opinions given by Nassimbeni (1998), Lor and Britz (2007) and other authors such as Martin (1995) and Webster (2002) attest to a general view that the information society has evolved over time. Despite all these arguments, one has to look also at the definition of the concept as presented at the World Summit on the Information Society (WSIS) in Geneva in 2003 to establish if the concept"s definition has evolved over time. The World Summit on the Information Society (WSIS 2003) in Geneva defines the information and knowledge society as a society in which people interact with technology as a fundamental part of life and social organisation to exchange information on a global scale. The information and knowledge society has been brought about by the

\footnotetext{
1. Glenrose V. Jiyane is a Senior Lecturer in the Department of Information Science, University of South Africa.

2. Mabel K. Majanja is a Professor at the School of Arts, University of South Africa.

3. Bertha J. Mostert is an Associate Professor in the Department of Information Studies, University of Zululand, South Africa.

4. Dennis Ocholla is the Head of the Department of Information Studies, University of Zululand, South Africa.
} 
transformation and evolution of previous societies and the use of tools for development (e.g. the Stone Age, Bronze Age, the Industrial Revolution). This society revolves around the use of information and communication technologies (ICTs). It offers many opportunities and benefits to people in terms of the facilitation of information creation, distribution, diffusion, access and use for growth and development in various spheres of life. The use of tools for development has evolved from the industrial revolution in the late $18^{\text {th }}$ and $19^{\text {th }}$ centuries that saw the increased use of machines and developments in the mining industries, to the increased use of information and technology in the $20^{\text {th }}$ century, and major breakthroughs that sparked the evolution of the information and knowledge society of the $21^{\text {st }}$ century. The basis of the information and knowledge society revolves around technology"s increased assimilation and diffusion in human society, particularly ICTs and their rapid growth and use in the exchange of information and knowledge.

\section{The role of information and knowledge society to informal sector women entrepreneurs}

The information and knowledge society offers enormous opportunities and benefits to people with regards to being able to access and use information. Opportunity refers to the formal and informal contexts within which actors operate. Opportunities brought about by the information and knowledge society present possible convenient contexts, among other things, within which communities and individuals, such as female entrepreneurs in the informal sector, can envisage options and choices to help their growth. In this way, they could gain economic empowerment. Economic empowerment is the process of availing basic economic opportunities for marginalised people. It is crucial because it mobilises the selfhelp efforts of the poor rather than providing them with social welfare as we normally observe in developing countries, including South Africa. Marginalised people have limited opportunities for self-sufficiency and depend on the government for grants and welfare or on charities for basic help and amenities. While categorising the "marginalised community" in the introduction of the IFLA social responsibility discussion group that was held in Amsterdam, Ocholla (1998) distinguishes between five groups, but only the third and fourth groups are discussed here. These groups are those who are marginalised or disadvantaged because of cultural and social poverty, especially the illiterate, the elderly, women and children, and those who are discriminated against by race, ethnicity, creed and religion. In many instances, lack of opportunity creates barriers to developing communities and individuals because it prevents them from leveraging the benefits brought about by the information and knowledge society. These benefits include access to ICTs to obtain information from local, regional and global information and knowledge systems. Economic empowerment lifts the burden from the government and enables people to stand up for themselves rather than rely on the government"s resources, which are not sufficient in many cases.

Information and knowledge also have a central role to play in sustainable development, in particular in contributing to poverty alleviation and income generation, the empowerment and consolidation of democracy and sustainable health, and the protection of the environment (Khan 2003: 20).

\section{Criteria and indicators of an information and knowledge society}

According to Holmner (2008: 69), a discussion of criteria is crucial because if a developing country or community does not meet specific criteria, then this failure becomes a barrier to the country"s or community"s progress towards becoming an information and knowledge society. With this in mind, authors such as Martin (1995), Webster (2002) and Britz et al. (2006) have suggested certain criteria that have to be met in order for a country or community to be considered an information and knowledge society. According to Holmner (2008: 69) the criteria can be applied to countries, and if a country meets the majority of these criteria, it can be deduced that the country has achieved the status of an information and knowledge society. However, if most or all of the criteria are not met by a country, as is often the case with developing countries, it can be concluded that the country is not on the path to becoming an information and knowledge society and can accordingly not benefit from the advantages of being included within this society.

In order to see how befitting the criteria are to an ideal information and knowledge society, the following definition has been adopted by Holmner (2008: 69) and will be adopted in this paper as well:

[An information and knowledge society is] a society that is reliant upon a sophisticated physical and ICT infrastructure for the improvement of everyday living and working conditions. This society values the importance of information as the key to economic wealth and prosperity, leading to an increase in information-related activities as well as an enhancement of intellectual capability. Information and knowledge ensures the freedom of information through the use of ICTs.

From this definition, the following criteria can be deduced (Holmner 2008: 70): economic criterion; spatial and technological criteria; political criterion; social criterion; cultural criterion; physical infrastructure criterion; and knowledge criterion.

\subsection{Economic criterion and its indicators}

For a country to be stable economically, it needs a strong and high gross domestic product (GDP) with low inflation in order for its citizens to afford basic amenities and enjoy a better quality of life. According to Martin (1995), information in the information and knowledge society is the key to economic prosperity, and is viewed as a resource, service, commodity, and a source of added value and employment. Britz et al. (2006: 27) explain that knowledge is the primary input in economic activities within the information and knowledge society, resulting in a new economy of information. 
Because information is regarded as having economic value in the information and knowledge society, it can be used to promote human development in areas of health, education, social services and commerce. In this way, it can be used to stabilise the economy and lower the unemployment rate because the majority of the population will use information to their benefit and for upliftment. Therefore, the application of ICTs in the information and knowledge society can be used for information exchange and sharing which can lead to the improvement of daily working and living conditions.

The first indicator of the economic criterion is work opportunities that lead to better income opportunities. Work opportunities strengthen the economy of a country. The measure of the work opportunity indicator is the unemployment rate of a country. Through ICTs, people can access the internet and browse for jobs that are available in their own country and in other countries. They are also able to share and exchange this information with each other, thus increasing the number of people who become aware of these employment opportunities. Mobile phones and websites are examples of communication devices that can be used to advertise employment opportunities. This contributes towards lowering the unemployment rate in a country.

The second indicator of the economic criterion is the standard of living of the people. This indicator is measured by income, inequality, poverty rate and real income per person. The previous indicator relates to this one as people who are employed or have opportunities for better employment, improve their standard of living and are no longer dependent on government grants. This improves the economy of the country.

Informal sector women entrepreneurs (ISWEs) are women who work in the sector of the economy that employs a handful of workers who earn low income, utilise rudimentary or subsistence technology and operate largely outside the boundaries of government laws and regulations governing business in general such as listed standards of quality, minimum pay and safety (Bangasser 2000).

The informal sector covers a wide spectrum of economic activities including retail, trade, construction, wood and metal work (Aluko 2003: 195). In Nigeria for example, Ekpo and Umoh (1998) divided the informal sector into productive, service and financial sub-sectors. The informal productive sub-sector, according to these authors, encompasses all economic activities involving the production of tangible goods such as agricultural production, mining and quarrying (excluding petroleum), small scale manufacturing, building and construction, woodwork, furniture making, garment making, and welding and iron works, among others. The informal service sector includes repairs and maintenance, informal education services, health services, counselling services, and manual labour. Repairs and maintenance services include tailoring, vehicle repairs and maintenance, carpentry and services in various households, and commercial tools. Informal health services, especially in rural areas, include traditional birth attendants, herbalists and other traditional medical practitioners. There are also traditional spiritualists who offer counselling services.

Lastly, Ekpo and Umoh (1998) observed that the informal financial sub-sector activities are mostly underground, unofficial, irregular, informal, shadowy and parallel. The predominant type of informal finance in Nigeria (that they observed), is the esusu. These are informal money lenders who are believed to be highly exploitative, charging high interest rates through which they extract economic surplus provided by peasant labour, capital, land and also savings and credit associations and credit unions.

In South Africa, informal sector activities include spazas, tuck shops, hawkers, street vendors, shebeens, kiosks, takeaways and fast food outlets, to name a few (Ligthelm and van Wyk 2004: 10). On the same note, Bangasser (2000: 9) observes that the popular view of informal sector activities is that they are primarily the activities of petty traders, street hawkers, "shoeshine boys" and other groups that are underemployed on the streets of big towns. Ligthelm and van Wyk (2004: 10) further note that some informal businesses are established on private property, for example the spazas, shebeens and tuck shops in townships. Additionally, Lalthapersad-Pillay (2004: 22) confirms that many people operate in the informal sector as hawkers and vendors, and adds subsistence farmers to the list; all of these groups generate income that is way below the poverty line.

Therefore, ISWEs could benefit from utilisation of ICTs such as computers and mobile phones to access information relating to their businesses, search for better jobs, access training opportunities and also advertise their sales.

\subsection{Spatial and technological criteria and its indicators}

The technological criterion is one of the four criteria identified by Britz et al. (2006) as pillars of a knowledge society. Therefore, information can be accessed at any time (Goddard 1991) as long as the spatial criterion, described by Webster (2002) as the changing meaning of space, place, time and distance, is present.

Sound technological infrastructure is vital for ICTs and connectivity. According to van Audenhove et al. (1999), technological infrastructure refers to the implementation of (among other things) integrated broadband networks which remove the barriers of time and space. However, these authors notice with disappointment that in many parts of the developing world, these networks are not yet in place. The spatial criterion, which focuses on the development of different types of networks and their effects on the organisation of time and space, is likewise still in progress.

The first indicator of the spatial and technological criteria is access to, and the use of, personal computers. In an information and knowledge society, people possess computers and are able to use them in their homes or at work. This indicator also relates to the economic criterion, where in order for people to afford a computer, for example, they should be working or have a job that will raise money to buy a computer. It also relates to the social criterion in the sense that children should be in good schools that have infrastructure and computers for them to learn computer skills and thereafter access and use computers for their school assignments. 
The second indicator of the spatial and technological criteria is closely tied to the first but is more focused on connection. The access and use of a computer is more fruitful when the computers are connected to a network that offers internet access. The internet and computers require good infrastructure and sound technology. Connection to the internet via computers allows people to share and disseminate information quickly and more easily. This indicator therefore looks at the speed and effectiveness of sharing and access to information.

Another important factor is that of telecommunications. There should be strong telecommunications in terms of fixed lines and mobile networks to support penetration. In this way, information and knowledge interaction among people would improve.

ISWEs could benefit from strong infrastructure. Connectivity is vital and therefore patchy networks due to weak infrastructure are an obstacle. Constant connection to suppliers, customers and other fellow women makes it easier for them to disseminate and share business-related information quickly and conveniently.

\subsection{Political criterion and its indicators}

In 2000, the South African government passed an Act that promotes access to information, called the Promotion of Access to Information Act (PAIA) of 2000 (Promotion of Access to Information Act, No. 2 of 2000: 2). This is evidence of a realisation by the government that access to information is important. In an information and knowledge society, the government ensures that citizens are not denied access to information, but rather enjoy timeous access to government information in order to participate meaningfully in debates and government proposals or green papers and assist in upholding the freedom of expression. A number of government activities can also be performed through ICTs and more and relevant government information could be accessed by needy citizens when systems to access information are in place. Kwake (2007) likewise observes the benefits of ICTs as enablers of the better delivery of government public services in areas such as health and education.

The announcement of voting results has improved with the application of technology. This has led to results being immediately released at the completion of the voting exercise. This accomplishment is attributed to ICTs connecting the various voting stations. Likewise ICTs and Research and Development (R\&D) strategies enable increased public and private participation (Maredi 2012: 6). For example, R\&D strategy supports e-governance, modernised government and e-participation in the political arena and provides a mechanism to forecast technology developments in targeted areas, market trends and potentials and also investments (Maredi 2012:6). Such R\&D strategies enable citizens to respond to matters in government publications, announcements, and call for participation with bills and other government matters and to also participate in their economic business objectives.

An important indicator of the political criterion is a high level of democracy. With democracy, people enjoy the right to freedom of expression, intellectual property rights, and the freedom to access information. A country in which people are not afraid to voice their thoughts and express themselves has achieved a high level of democracy. In such a democracy, people know that they have the right to access information. This promotes information and knowledge sharing, which improves the way they perceive and even understand things. ISWEs could exercise their human rights better and have access to government information more efficiently.

\subsection{Social criterion and its indicators}

According to Martin (1995), information in the information and knowledge society enhances the quality of life. Decisionmaking and action are a measure of the usability of information, meaning that information has to be both relevant and timely (Holmner 2008: 79). Holmner (2008: 79) also suggests that the pricing of the internet connection used to access information is a measure of the affordability of information. The author emphasises that information should be viewed as a factor that enhances the quality of life within the information and knowledge society. This can be achieved by developing human intellectual capital and improving health, education, social services and commercial activities through technology and the dissemination of high quality information along information superhighways (Holmner 2008: 74). Regarding education, ICT R\&D strategies enhance e-education which is supported by mobile and wireless devices (Maredi 2012: 6). On the subject of health matters, e-health could be possible with these ICT R\&D strategies, where health information will be delivered more quickly and easily with the application of ICTs in different aspects of health services.

One indicator of the social criterion is the health of the citizenry. This indicator looks at the mortality rate of citizens. It is important to assess the life span and mortality rate of citizens because this provides an indication of the state of the country. This indicator also reflects the general quality of life. For citizens to have a low mortality rate there should be a number of medical practitioners who take care of the health of the citizenry.

The other indicator of the social criterion is education opportunities. This indicator is measured by looking at literacy levels and the number of years that education is compulsory in a country. If a country compels children to remain in school for a number of years, more people will receive education, and this will ultimately improve the literacy levels of that country.

A further indicator of the social criterion is the development of modern public services, for example initiatives where government information is available and can be accessed online; health services that are supported by technologies, such as health information that is available online; and initiatives in education such as distance learning.

In fully-fledged information and knowledge societies, electronic voting systems allow people to vote online, and other initiatives improve the level of people"s understanding of the government and its systems. In the health system, health information can be shared and disseminated speedily because it is available online, and people have access to such information because they have computers and can access the internet on their own. 
Regarding education, ICTs support electronic learning where learning materials are uploaded online or delivered online. This indicator also relates to the spatial and technological criteria because the gap between space and time is narrowed.

The fourth indicator of the social criterion is usable content. This indicator has six sub-indicators which are adopted from Britz et al. (2006), namely that in the information and knowledge society, information should be available, affordable, timely, relevant, readily assimilated, and in a language the user can understand.

The availability of information is also closely related to the spatial and technological criteria where ICTs support access and the speedy sharing and interaction of information and knowledge.

The affordability of information relates to the economic criterion. It depends on whether people can afford ICTs to access and use the information they need. This in turn requires a look at the economic status of a person, a family or a community, and whether they are employed or not. If not, they cannot afford to purchase computers and stay connected to networks. Thus affordability looks at the pricing of information and the pricing of ICTs that promote access to information.

Delivering relevant information looks at the timeframe and whether information is delivered in a language that is understood by the user. This relates to the spatial and technological criteria in that it is very important for information to be relevant and accessible anywhere, even in remote areas.

\subsection{Cultural criterion and its indicators}

In Nassimbeni"s (1998: 154) definition of the information and knowledge society, she emphasises that the information and knowledge society serves the cultural enrichment of all citizens through the diversity of content that reflects linguistic and cultural diversity, and this is essentially the cultural criterion. The use of ICTs could support international exposure of the country because the exchange and sharing of information and knowledge pertaining to a country"s culture, beliefs, norms, values and religions would take place easily.

Singh (2005: 680) also notes that technology has an impact on culture in the sense that it creates new means of cultural expression and exchange, and offers opportunities for knowing, learning and disseminating the culture on a global scale.

The indicators of the cultural criterion include linguistic diversity, cultural heritage, and the preservation of cultural legacy. According to Nassimbeni (1998), the information and knowledge society supports, serves and enriches culture by accepting linguistic, content and cultural diversity.

The information and knowledge society promotes linguistic diversity where both local and global languages are promoted for the sharing of information and knowledge. People in the information and knowledge society respect each other"s diverse heritage and promote and preserve their cultural legacies and heritage. They also set aside a day or month to celebrate their different cultures because they enjoy freedom of expression and do not have anything to fear. This, in turn, ties into the political criterion. The government in an information and knowledge society recognises the role of indigenous people in the economy of the country, especially through tourism. Therefore, these indicators also relate to the economic criterion.

ISWEs could benefit by using online marketing strategies to promote their cultural food, attire and activities with the use of ICTs. This could expose what they have and do and how they do it. This could attract international tourists and tourists from distant parts of their own country who search the internet and find this diverse rich culture of activities in their local stores. Through them, their economy improves and heritage is promoted. However, this benefit is minimal to ISWEs, as most of them do not get to know of or get invited to participate in national and local expos, or use ICTs to search for announcements and invitations to showcase in these expos.

\subsection{Physical infrastructure criterion and its indicators}

Proper roads, airlines, railway lines and other related infrastructure are part of physical infrastructure, and their presence promotes mobility and the delivery of people, goods and services from one place to another in a community or country, or even outside the country. According to Britz et al. (2006: 27), many policy-makers forget that the information and knowledge society is still underpinned by reliable and highly-sophisticated infrastructure. As a result, the infrastructure aspect is overlooked and its importance is under-emphasised. Therefore accessible airports, roads, railways, harbours as well as different modes of transport are needed so that this infrastructure can be used for transportation (Holmner 2008: 82). The author concludes that although the physical infrastructure criterion does not have a direct impact on the interaction and exchange of information and knowledge, this criterion is still important because it has a direct bearing on some of the other criteria in the information and knowledge society, and therefore on information and knowledge exchange and sharing.

The indicators of the physical infrastructure criterion look at the transport system of the country, the number of motor vehicles, the availability of railway lines, air transport, and the conditions of the roads across the country. The road supports the flow of transportation of people, goods and services within and around the country, and only strong and sound infrastructure makes this possible. The number of motor vehicles also means that people can afford to buy them, an indicator of the economic criterion.

The proliferation of railway lines and airports ensures the timely mobility of people, goods and services both within and outside the country, and thus promotes information and knowledge sharing. This also boosts the economy of the country because it supports tourism. Adequate transport, be it road, railway or air, also makes transport cheaper in the country, which means that virtually everyone can afford to travel. To ISWEs, this also could mean saving a lot of money, 
energy and time waiting for transportation to take them to their stalls, instead of investing this money, energy and time in their businesses. Adequate transport could also ensure that their perishable products are distributed quickly while still fresh. This could increase their business gains.

\subsection{Knowledge criterion and its indicators}

Access to information is crucial for development. According to Khan (2003: 20), access to information highways and to content such as development data and information is still a major problem in many countries. Khan (2003: 20) is, however, of the opinion that if all people, including disadvantaged and marginalised groups such as people with disabilities, indigenous people or people living in extreme poverty, and also women and the youth, could access information and equally benefit from ICTs, they would be able to network, share information, create knowledge resources, and develop skills that could help them live and work in the new digital environment.

Evidently there is a crucial relationship between information and development. However, Mncube (2003: 6) laments that the failure to recognise this vital role of information within the development arena has negative consequences for development, most notably in developing communities.

The indicators of the knowledge criterion include information and computer literacy, sophisticated ICT infrastructure, and the creation of local content and local e-content.

One indicator, information and computer literacy, addresses the issue of the number of people in the country who are equipped with the skills to search for information and use computers for information access. This requires a certain literacy level. In the information and knowledge society, people are able to surf online for information and choose from the vast range of options available.

Sophisticated infrastructure is another indicator. It addresses the issue of the flow of information to everyone everywhere due to the availability of ICTs. Sophisticated infrastructure enables people to share and communicate local and global information. This indicator overlaps with the spatial and technological criteria.

The creation of local content is the third indicator of the knowledge criterion. According to WSIS (2003), people are encouraged to create and share their local content and e-content through ICTs and in their own languages to promote inclusion in the information and knowledge society.

Therefore in the information and knowledge society, information and computer literacy is crucial to the access, sharing and dissemination of information and knowledge using sophisticated ICTs. In this way local information, heritage and language is shared with people globally. ISWEs could benefit by exercising their computer and information literacy skills. They would be able to search for information they need quickly from their computers with access to the internet.

\section{South Africa as an information and knowledge society: benefits to ISWEs}

In the section, the criteria and indicators of an information and knowledge society are applied to South Africa to determine where it stands as such a society, and the benefits to ISWEs are discussed.

\subsection{Assessing the economic criterion}

As already mentioned, a strong economy is determined by the availability of job and employment opportunities. The unemployment rate in South Africa has declined from $25.5 \%$ in 2006 to $23.3 \%$ in 2011 (see Table 1). Globally, South Africa is ranked in $170^{\text {th }}$ place in terms of unemployment ("Unemployment, youth age" 2011).

Table 1 Decline in the unemployment rate in South Africa between 2003 and 2011

\begin{tabular}{lcccc}
\hline Year & Unemployment rate & Rank & Percentage change & Date of information \\
\hline 2003 & $37.00 \%$ & 18 & & 2001 est. \\
2004 & $31.00 \%$ & 24 & $-16.22 \%$ & 2003 est. \\
2005 & $26.20 \%$ & 161 & $-15.48 \%$ & 2004 est. \\
2006 & $25.50 \%$ & 168 & $1.53 \%$ & 2005 est. \\
2007 & $25.50 \%$ & 172 & $-4.14 \%$ & 2006 est. \\
2008 & $24.30 \%$ & 169 & $-4.71 \%$ & 2007 est. \\
2009 & $22.90 \%$ & 170 & $-5.76 \%$ & 2008 est. \\
2010 & $24.00 \%$ & 173 & $4.80 \%$ & 2009 est. \\
2011 & $23.30 \%$ & 170 & $-2.92 \%$ & 2010 est. \\
\hline
\end{tabular}

Source The World Factbook 2012

Although the South African economy is improving, a low standard of living and a high rate of poverty still exists, especially in rural areas and among women. South Africa is ranked $23^{\text {rd }}$ with respect to poverty, with $0.45 \%$ of the world"s poor ("Economy Statistics: poverty" 2010). According to Ozoemena from Consultancy Africa Intelligence (CAI) (2010), although there are plans to fight poverty in South Africa in rural areas, there is still a high rate of unemployment and poverty. The author further explains that many existing policies deal mostly with the formal sector to the detriment of informal, non-remunerative roles that rural women perform. It therefore does not fully meet this criterion. This shows that 
ISWEs do not benefit from the status of South Africa in this regard. Their personal information, level of education, and skills in using ICTs deter them from fully benefiting. So their standard of living could improve slightly since they are selfemployed. However, the fact is that they need support and further assistance to sustain themselves and their business by ensuring that the ICTs are user-friendly and their skills are improved through further training. Their income generation could improve and thus poverty could be slightly alleviated.

\subsection{Assessing spatial and technological criteria}

These criteria focus on ICTs and related technology that support access to, and the use of, computers, the internet and telecommunications. In 2001, it was estimated that there were approximately sixty-six personal computers per 1,000 people in South Africa, and the number increased to eighty-five personal computers per 1,000 people within five years (World Bank 2005). When comparing South Africa to other African countries such as Kenya (fourteen), Tanzania (nine), Uganda (ten) and Zimbabwe (sixty-eight) (World Bank 2005), this is a positive indication given its population of 50.59 million (Statistics South Africa 2011: 3).

However, things take a turn for the worse when comparing South Africa to countries such as Switzerland, where 864 per 1,000 people had access to personal computers in 2005 ("Personal computers" 2005). Based on this comparison, the number of people with access to computers is too low in South Africa for it to be categorised as an information and knowledge society. Nevertheless, it is acknowledged that the South African government is doing its best to increase the number of people with access to personal computers. For example, an initiative focusing on rural areas is in progress to place ICTs, including computers, in centres within rural people"s reach (Snyman \& Snyman 2003: 96), and to date, there is significantly increasing literature alluding to the increasing number of people that have access to computers, for example, as indicated in sections below.

With respect to internet access and use, Internet World Stats (2012) estimates that there were 8,500,000 internet users in South Africa in 2012, an increase from 4,590,000 in 2008. Although these numbers indicate that many people in South Africa have subsequently been able to access and interact, share and disseminate information and knowledge in education, health, economy and politics in the global information and knowledge society, the figures are still very small, and internet use is still inadequate, especially in rural areas. Thus it can be concluded that South Africa does not meet this criterion.

Another indicator is access to broadband services. This provides internet users with high-speed internet access, which is extremely important in the information and knowledge society. The Organisation for Economic Co-operation and Development (OECD) released its statistics for 2012, which include the number of broadband subscribers per country, broadband subscription by technology, and percentage of fibre connections in total broadband (OECD 2012). For South Africa there were $321,317,973$ fixed broadband subscriptions in June 2012 in the OECD area, with DSL at 175,941,671 $(54.8 \%)$, cable modem at $97,603,719(30.4 \%)$, fibre and LAN at $45,744,330(14.2 \%)$ and "other" at $2,028,253(0.6 \%)$, which was up from 294 million in June 2010 (OECD 2012).

MyBroadband (2012) lists Vodacom, Telkom SA, MTN, iBurst and Neotel as South Africa"s broadband providers, and in its report, Vodacom is the largest South African mobile network operator and the most respected broadband provider in the country, with iBurst the worst provider. Although the broadband service is recognisable in South Africa, it is ranked at number 104 out of 172 countries when it comes to fixed broadband penetration rates. With only 1.8 fixed broadband subscriptions per 100 inhabitants in 2011, South Africa is ranked lower than countries such as Tunisia, Mauritius and Egypt (MyBroadband 2012). However, South Africa, performed better when it came to mobile broadband, with 19.8 active mobile broadband subscriptions per 100 inhabitants. It was ranked at number forty-seven out of 177 countries in 2011 (MyBroadband 2012). The MyBroadband report further revealed that 9.8 out of 100 households in South Africa have internet access. South Africa was ranked at number sixty-four out of 127 developing countries for households with internet access. With twenty-one out of 100 individuals using internet in South Africa, it meant that the country was ranked at 109 out of 177 countries, which is a ranking below countries such as Morocco, Kenya, Mauritius and Egypt (MyBroadband 2012).

Table 2 indicates that South Africa"s figures are nowhere near those of the top ten selected countries, although the number of broadband subscribers is growing. It can therefore be concluded that South Africa does not comply with the broadband indicator.

The level of telecommunication penetration is also very important as an indicator of an information and knowledge society. South Africa has seen a decrease of $1.0 \%$ in fixed lines between $2001(4,924,500)$ and 2006 (4,729,000) (International Telecommunications Union 2006). This decrease is perhaps related to the marked increase in mobile penetration, as this has grown significantly over the past few years.

Although not many mobile subscribers are able to use digital services in South Africa because of the cost, South Africa complies with this indicator although, overall, South Africa does not comply with many of the indicators within this criterion. Hence ISWEs are not benefiting. They do not have personal computers or access to the internet at all times. Very few possess fixed landlines. Those who have mobile phones have the kind that cannot perform mobile banking and other activities performed when a person has access to the internet. Even if they had skills to perform digital services, they cannot to do so with the type of mobile phones they possess. 
Table 2 Selected top ten countries in terms of OECD fixed (wired) broadband subscriptions per 100 inhabitants, by technology, June 2012

\begin{tabular}{lllllll}
\hline Rank country & Fibre/LAN & DSL & Cable & Other & Total & Total subscribers \\
\hline 1 Switzerland & 1.4 & $28.1 \%$ & $11.8 \%$ & $0.4 \%$ & $41.6 \%$ & $3,276,700$ \\
2 Netherlands & 1.8 & $20.1 \%$ & $17.5 \%$ & $0.0 \%$ & $39.4 \%$ & $6,573,000$ \\
3 Denmark & 6.0 & $21.1 \%$ & $10.6 \%$ & $0.2 \%$ & $38.3 \%$ & $2,131,167$ \\
4 Korea & 21.6 & $4.6 \%$ & $10.0 \%$ & $0.0 \%$ & $36.2 \%$ & $18,010,256$ \\
5 Norway & 7.3 & $17.8 \%$ & $10.9 \%$ & $0.1 \%$ & $36.1 \%$ & $1,789,279$ \\
6 France & 0.4 & $33.0 \%$ & $2.2 \%$ & $0.0 \%$ & $35.5 \%$ & $23,167,000$ \\
7 Iceland & 6.6 & $27.7 \%$ & $0.0 \%$ & $0.0 \%$ & $34.3 \%$ & 109,359 \\
8 Germany & 0.2 & $28.7 \%$ & $4.8 \%$ & $0.1 \%$ & $33.8 \%$ & $27,677,770$ \\
9 United Kingdom & 0.9 & $26.0 \%$ & $6.6 \%$ & $0.0 \%$ & $32.6 \%$ & $21,066,624$ \\
10 Belgium & 0.0 & $16.9 \%$ & $15.7 \%$ & $0.0 \%$ & $32.7 \%$ & $3,586,116$ \\
\hline
\end{tabular}

Source OECD 2012

\subsection{Assessing political criterion}

For a country to meet this criterion as an information and knowledge society, it has to have a high level of democracy to facilitate and promote the rights of citizens such as the right to freedom of information, the right to freedom of expression, and intellectual property rights. These rights, when available to citizens, have the effect of increasing the level of participation in government, which in turn leads to the better sharing of information and knowledge. Government information and voter information in an information society is more transparent and delivered and announced with more ease to people.

In 2000, South Africa effected the Promotion of Access to information Act (PAIA). The aim of this Act is to give South African citizens the information they need to exercise and even protect their rights. The Act promotes transparency and supports citizens who need access to government information and records. Overall, South Africa appears to be complying with this criterion, as South African media and political affiliates are pushing this agenda of transparency and access to information. However, continuous monitoring of minor incidents is necessary to ensure that there is total access to the government information that citizens require, that journalists have freedom of expression and speech, and that intellectual property rights are observed and adhered to.

Although South Africa is a democratic country, ISWEs may not be in a position to express themselves freely due to their status in the community, first as women and second as informal sector workers. They may need someone to voice their concerns on their behalf. They may not be able to view government bills in order to understand, and hence to exercise, their rights, and fully participate owing to the fact that they do not have time to access such information because of their long working hours. Access to state publications that could assist them may also be restricted because most of the publications are in English. Hence they are not benefiting from this criterion.

\subsection{Assessing social criterion}

Freedom House (2011) reveals that there were fifty-three deaths per 1,000 live births in 2007 compared to fifty-four in 2001 in South Africa. According to Statistics South Africa (Stats SA) (2011: 3), in mid-year population estimates for 2011 there was a $37.9 \%$ infant mortality rate. This is a decline from the $48.2 \%$ infant mortality rate in 2009 and $49.3 \%$ in 2008 . Accordingly, the life expectancy at birth in 2011 stood at $54.9 \%$ for males and $59.1 \%$ for females (Stats SA 2011: 3). This suggests that South African health services are improving and people"s health conditions are becoming better. But this can also be measured in terms of the number of medical practitioners in the country who are able to take care of people"s health and lives.

NationMaster (2004) estimated that there were 0.77 physicians in South Africa per 1,000 people; South Africa was sixteenth out of 148 countries whose statistics were available in 2004. There are prepaid plans as a percentage of private expenditure on health of $77.7 \%$, and in this regard, South Africa ranked first out of 159 countries ("Health statistics" 2004). However, even with many practicing medicine, South Africa has yet to achieve the social criterion of the information and knowledge society.

Most of the health-related publications available to citizens are in English, which benefit a few people but not necessarily ISWEs. Another respect in which they could benefit is from health and education. However, the government employees" medical scheme does not cater for ISWEs since they are self-employed. Therefore, their health may not be fully taken care of and they could get a low-service health care. From their category and that of their families, life span and mortality may be short and high.

With regard to education opportunities, ISWEs, especially those who could still attend formal schooling, do benefit from night schools which take place in the evenings. However, often they are tired from long working hours (Jiyane and Mostert 2008:89), and, further, this is the time for them to cater for their families. Hence they do not benefit from such opportunities, whenever these opportunities are present. 


\subsection{Assessing cultural criterion}

Linguistic diversity, cultural heritage and preservation of cultural legacy are all indicators of the cultural criterion. South Africa is inhabited by different cultural groups with different languages and heritage. The South African government is committed to protecting and preserving all the country"s diverse cultures, languages, heritage and beliefs without discrimination because they all contribute to local content, indigenous knowledge, democracy and tourism. The South African government is improving its efforts to make the information on different cultures, heritage and languages accessible by supporting museums, libraries and centres where this information can be accessed. Heritage sites are preserved and cultural rituals are respected and can be performed in the country. For example, in 2011 King Goodwill Ubhejane Phumesiqiwini"s mother was reburied on the site where all the other kings are resting in Umkhumbane ("Zulu queen mother reburied" 2011).

There are many languages spoken in South Africa, but only eleven are official. Although there are many different languages in South Africa, English is generally understood across the country because it is the language of business, politics and media. However, people in rural areas and marginalised communities, where most ISWEs are found, really struggle with the language and subsequently cannot benefit from the information and knowledge society. Thus South Africa complies with all the indicators of the cultural criterion, except perhaps with language. With this criterion, ISWEs benefit minimally.

\subsection{Assessing physical infrastructure criterion}

This criterion refers to well-developed physical infrastructure in terms of railways, roads, airports and harbours which are necessary in an information and knowledge society to improve the communication between people, the movement of goods, services and people, and the dissemination of information and knowledge. Although travelling by road seems to be the cheapest and only alternative mode of transport and also the most used in rural areas where there are no other means of sophisticated transportation, this is not always the case.

According to Gwilliam et al. (2008: 3), roads provide basic connectivity between primary and secondary cities and key ports and land border crossings. The current road density in Africa is estimated at $6.84 \mathrm{~km}$ per $100 \mathrm{~km}$, indicating the general inadequacy of road infrastructure. However, in 2009, South Africa had a total of 362,099km of road and was rated eighteenth globally, a total of $20,872 \mathrm{~km}$ of railway and rated fourteenth out of 134 countries, and a total of 607 airports and one heliport ("Africa: South Africa: transportation" 2010). According to NationMaster (2010), there were 146 motor vehicles per 100 inhabitants as of 28 December 2010, and a total of 8, 047,331 motor vehicles in the country.

South Africa has three international airports, namely OR Tambo in Johannesburg, King Shaka in Durban, and Cape Town International. According to Wikipedia (2012), OR Tambo International Airport is the busiest airport on the continent and is regarded as the air transport hub of Southern Africa. It employs 18,000 people who are employed by various companies at OR Tambo, and the airport plays a key role in the Gauteng province"s economy (VenturesAfrica 2012). South Africa also has seven national airports and 721 regional airports. In total, there are 731 airports within South Africa. This large number of airports has won the country tenth place in the world ("South Africa: transportation" 2012).

Railway transport has also remained very important in South Africa. Although it is the slowest kind of transport, it is affordable and reliable and is still being used to transport people and goods, particularly large amounts of heavy goods. According to the The World Factbook (2012), in 2008 there was a total length of 20,192km of railway in South Africa, placing it at number fourteen out of 134 countries.

The physical infrastructure criterion also relates to the tourism industry and thus to the GDP of the country"s economy. When a country has adequate and sound roads, railways, airports and harbours, it attracts more tourists which brings money into the country. This also means more people will reach places within and outside the country as fast as possible. This affects the quality of life of the people and thus improves their living standards.

South Africa therefore has a sound, adequate and sophisticated transportation system which is used to transport people and goods within the country and beyond. South Africa is therefore in compliance with the physical infrastructure criterion. However, in many rural places of SA, road infrastructure within communities, which lead from national roads, are still in a very poor condition. Poor road infrastructure deters ISWEs from benefiting. They cannot quickly get to their work places and to the suppliers should there be something urgently needed. With the money they generate, even if the transport was present in their vicinity, it would not be easy to take the faster mode of transport such as railways, airplanes or their own vehicles. In fact for emergency, many of them use wheelbarrows for transportation. Therefore, they do not benefit from the physical infrastructure criterion.

\subsection{Assessing knowledge criterion}

Information sharing and dissemination is fundamental in the information and knowledge society. Nowadays there are ICTs that facilitate this process, which means that the infrastructure should be present as well. Over and above the infrastructure, people should have acceptable levels of literacy and skills to interact with these ICTs in order to access information and knowledge. Therefore literacy, both information and computer literacy, is crucial for people to interact, access and use information in the information and knowledge society.

The literacy rate in South Africa, i.e. reading and writing, stood at $86.4 \%$ in 2012 (87\% male and $85.7 \%$ female) ("List of countries by literacy rate" 2012). South Africa has many projects running that aim to equip people with the skills necessary to function in the information and knowledge society. Various authors have discussed these projects and initiatives, for example, Jiyane and Onyancha (2010), Machet and Wessels (2006), and De Jager and Nassimbeni (2007, $2005,2003,2002)$. These authors discuss the commitment by the South African government, NGOs, institutions of higher 
learning, libraries and families and communities to the improvement of literacy levels. Thus initiatives towards an information literate South Africa are in place and in progress to meet this indicator of the information and knowledge society.

With respect to local content as an indicator of the knowledge criterion, South Africa is raising awareness of the importance of local South African content and there are initiatives to support this. Even in institutions of higher learning such as the University of South Africa (Unisa), there have been serious debates, such as support for the Department of Higher Education minister"s (Blade Nzimande"s) argument that the mother tongue should be used in teaching so that students may grasp concepts in their mother tongue before they switch to other languages as they progress with their studies. At Unisa, recent debates stress that local content is better conveyed through the mother tongue. Unisa is also in the process of writing the different languages glossary to improve teaching and learning ("Preparing South Africa"s youth: maths and science - is a home language the answer? Speech by the Minister of Higher Education, Blade Nzimande" 2011).

In order for government information materials to be accessible to many citizens, information is translated into many other languages, i.e. eleven official languages in South Africa. The South African Broadcasting Authority (SABC), in response to the call for promoting local content and indigenous knowledge, is in the process of adding two new channels, that is SABC4 and SABC5 (Gadebe 2005). According to the author, this initiative will cater for Sepedi, Sesotho, Setswana, Afrikaans, IsiZulu and IsiXhosa. With these initiatives in place, South Africa appears to be only partly complying with the indicators of the knowledge criterion because some of these initiatives are still work-in-progress, and thus they do not benefit ISWEs. The fact that these women do not own computers, and have limited search and computer skills does not allow the benefiting and growth space for them.

\section{Conclusions and recommendations}

In conclusion, South Africa complies with a few criteria and only partly complies with some. In some instances it does not comply at all with the criteria. In other words, South Africa is still in the process of becoming an information and knowledge society. Meeting all the criteria of an information and knowledge society would help South Africa improve the conditions of the country"s citizenry, in particular those who are marginalised and disenfranchised in the informal sector. For example, the infrastructure can support the growth of broadband, resulting in lower rates for subscribers. Women in the informal sector can be role players in many activities supported by technology and ICTs to the benefit of their informal businesses. Communication with suppliers and among themselves as business managers would significantly improve. In a fully-fledged information and knowledge society, they would be able to access other business services locally and internationally, which would lead to economic growth and improved employment and business opportunities (e.g. expanding networks in selling curio to tourists, comparing costs and prices to meet global standards).

ICTs are the basis of the information and knowledge society. They contribute to an environment for improved information access, use and dissemination by informal sector women entrepreneurs. In that way, their socio-economic environment is transformed. This paper has pointed out that infrastructure and relevant ICTs are in place to accelerate information access and use and flow in general. This infrastructure can support the connectivity of informal sector women entrepreneurs amongst each other and with their counterparts in other places of the world, therefore allowing information to be shared among themselves. Skills and knowledge to harness such opportunities for ICTs manipulation for development, empowerment and growth are also vital. It is recommended that informal sector women entrepreneurs should be equipped with such skills that will help them to survive in the current information and knowledge economy.

\section{References}

"Economy Statistics: poverty". NationMaster. 2004. [Online]. http://www.nationmaster.com/graph/eco_pov_sha_of_all_poo_peo-poverty-share-all-poor-people (27 July 2013 ).

"List of countries by literacy rate". Wikipedia. 2012. [Ōnline]. http://en.wikipedia.org/wiki/List_of_countries_by_literacy_rate (27 July 2013).

"Africa: South Africa: Transportation”. NationMaster. 2010 [Online]. http://www.nationmaster.com/red/country/sf-southafrica/tra-transportation (27 July 2013).

"Health statistics”. NationMaster. 2004. [Online]. http://www.nationmaster.com/graph/hea_phy_per_1000_peo-physiciansper-1-000-people (23 March 2011).

"Leapfrogging”. Wikipedia. 2010. [Online]. http://en.wikipedia.org/wiki/Leapfrogging (22 September 2010).

"List of busiest airports in Africa". Wikipedia. 2012. [Online]. http://en.wikipedia.org/wiki/List_of_the_busiest_airports_in_Africa (06 June 2013).

"Personal computers". NationMaster. $\overline{200 \overline{5}}$. [Ōnline]. http://www.nationmaster.com/country/sf-south-africa/med-media (23 March 2011).

"South Africa: transportation". The World Factbook. 2012. [Online]. http://www.cia.gov/library/publications/the-worldsfactbook/geos/sf.html (6 June 2012).

"Unemployment, youth age". The World Factbook. 2011. [Online]. http://www.cia.gov/library/publications/the-worldsfactbook/geos/sf.html (11 November 2010).

Abid, A. 2002. UNESCO and the World Summit on the information society. $68^{\text {th }}$ IFLA council and general conference. 1824 August 2002. Glasgow: IFLA.

Aluko, Y.A. 2003. Women"s employment and family stability in Nigeria: a survey of working women in Ibadan Metropolis. Olabisi Onabanjo University. 
Bangasser, P.E. 2000. The ILO and the informal sector: an institutional history. Geneva, Switzerland: International Labour Organization.

Barbour, R.R. 2008. Introducing qualitative research: a student guide to the craft of doing qualitative research. London: Sage.

Bell, D. 1974. Post-industrial society: the idea. In The information society Reader. New York: Harper Colophon Books. 238-239.

Britz, J.J., Lor, P.J., Coetzee, E.M.I. \& Bester, B.C. 2006. Africa as a knowledge society: a reality check. International information and library review, 38: 25-40.

De Jager, K. \& Nassimbeni, M.C. 2002. Institutionalising information literacy education: lessons learnt from South African programmes. Library trends , 51 (2): 167-184.

De Jager, K. \& Nassimbeni, M.C. 2003. An exploratory of the current status of information literacy tuition in South African tertiary institutions and prospects for curriculum design. South African journal of libraries and information science, 69 (2): 108-114.

De Jager, K. \& Nassimbeni, M.C. 2005. Information literacy and quality assurance in South African higher education institutions. Libri, 55 (1): 31-38.

De Jager, K. \& Nassimbeni, M.C. 2007. Information literacy in practice: engaging public library workers in rural South Africa. IFLA Journal, 33(4): 313-322.

Ekpo, I.A.H \& Umoh, O.J. 1998. The informal sector. [Online]. http://www.onlinenigeria.com/links/economy. (13 July 2007).

Freedom House. 2011. Countries at the crossroads: an analysis of democratic governance. Rowman \& Littlefield. [Online]. http://books.google.com (3 November 2011).

Gadebe, T. 2005. TV for local languages. SouthAfrica.info. [Online]. http://www.southafricainfo/ess_info/sa_glance/media/sabc-170605.html (15 April 2011).

Goddard, J. 1991. Networks of transactions. Times higher education supplement. 22 February.

Gwilliam, K., Foster, V., Archondo-Calloa, R., Bruceno-Garmendia, C., Nogales, A. \& Sethi, K. 2008. The burden of maintenance: roads in sub-Saharan Africa. AICD Background Paper 14, Africa Region. Washington DC: World Bank.

Holmner, M.A. 2008. A critical analysis of information and knowledge societies with specific reference to the interaction between local and global knowledge systems. Ph.D. Thesis. University of Pretoria.

International Telecommunications Union (ITU). 2006. World telecommunications/ICT development report of 2006. [Online] http://itu.int/dms_pub/itu-d/opb/ind/D-IND-WTDR-2006-SUM-PDF-E.pdf (22 March 2009).

Internet world stats: usage and population statistics. 2012. South Africa internet usage and marketing report. [Online]. http://www.internetworldstats.com (27 July 2013).

Jiyane, G.V. \& Onyancha, O.B. 2010. Information literacy education and instruction in academic libraries and LIS schools in institutions of higher education in South Africa. South African journal of libraries and information science, 76(1): $11-23$.

Jiyane, V. \& Mostert, J. 2008. The role of the library in economic empowerment and poverty alleviation among informal sector women entrepreneurs: a preliminary study in the Umhlatuze area. Mousaion, 26 (2): 79-97.

Kwake, A. W. 2007. The role of information and communication technologies in harnessing information for women in rural development: case studies of South Africa and Kenya. Ph.D. Thesis. University of Zululand.

Laltherpasad-Pillay, P. 2004. A socio-economic analysis of African female street traders in the Johannesburg CBD. South African journal of economics management sciences, 17(1): 22-44.

Ligthelm, A.A. \& Van Wyk, A.M.A. 2004. City of Tshwane metropolitan: informal trading in Tshwane - regulatory, spatial and economic framework; second draft report. University of South Africa, Pretoria: Bureau of marketing research.

Lor, P.J. \& Britz, J.J. 2007. Is a knowledge society possible without freedom of access to information? Journal of information science, 33(4): 387-397.

Machet, M. \& Wessels, N. 2006.Family literacy projects and the public library. Innovation, 32: 53-73.

Maredi, I. 2012. SA-EU collaboration in ICT: South Africa's ICT R\&D and Innovation Strategy. Paper presented in Berlin, Germany, 18 January 2012. [Online]. http://www.esastap.org.za/download/present_germany_01_2012.pdf (12 April 2012).

Martin, W.J. 1988. The information society. London: Aslib.

Martin, W.J. 1995. The information society. London: Aslib.

Mncube, S.S. 2003. The role of information in development. Development Bank of Southern Africa. Gauteng: Halfway House.

MyBroadband. 2012. The state of broadband in South Africa. [Online]. http://www.mybroadband.co.za/news/broadband/61094-the-state-of-broadband-in-south-africa (06 June 2013).

Nassimbeni, M. 1998. The information society in South Africa: from global origins to local vision. South African journal of libraries and information science, 66(4): 154-160.

Ocholla, D.N. 1998. The growing gap between the information rich and the information poor, both within countries and between countries. a composite policy paper. $65^{\text {th }}$ IFLA conference council and general conference. 20-28 August 1999, Bangkok. [Online]. http://www.ifla.org/IV/ifla65/papers.126-72e.html (23 March 2009).

Organization for Economic Cooperation Development (OECD), 2012. OECD Broadband statistics. [Online]. http://oecd.org/document/46/o,3746,en_2649_34225_39575J98_1_1_1_1,00.html (06 June 2013). 
Ozoemena, R. 2010. Poverty alleviation strategies in South Africa: creating dignified living for women through social justice and development. [Online]. http://consultancyafrica.com/index.php (23 March 2011).

Preparing South Africa"s youth: maths and science - is a home language the answer? Speech by the Minister of Higher Education, Blade Nzimande. 2011. University of South Africa (Unisa) electronic news. 24 May.

Promotion of Access to Information Act, No. 2 of 2000. 2000. Government gazette. 20852. Pretoria: Government Printer.

Singh, S. P. 2005. The role of technology in the emergence of the information society in India. The electronic library, 23(6): 678-690.

Snyman, M.E. \& Snyman, M.M.M. 2003.Getting information to disadvantaged rural communities: the centre approach. South African journal of library and information science, 69(2): 95-108.

Statistics South Africa. 2011. Mid-2011 population estimates. [Online]. http://statssa.gov.za. (11 January 2012).

Towards knowledge societies: an interview with Abdul Waheed Khan. 2003. UNESCO communication and information sector news service. 18 July. [Online]. http://www.unesco.org (21 August 2010).

van Audenhove, L., Burgelman, J.C., Nulens, G. \& Cammaerts, B. 1999. Information society policy in the developing world: a critical assessment. Third world quarterly, 20(2): 387-397.

VenturesAfrica. 2012. The ten biggest airports in Africa. [Online]. http://www.ventures-africa.com/2012/08/the-10biggestairports-in-africa/ (6 June 2013).

Webster, F. 2002. Theories of the information society. $2^{\text {nd }}$ edition. London: Routledge.

World Bank. 2005. What is IK? [Online]. http://www.worldbank.org/afr/ik/what.htm. (27 July 2013)

World Summit on Information Society. 2003. Declaration of principles (WSIS) [Online]. http://www.itu.int/wsis/geneva/official/dop/html (07 April 2010).

Zulu queen mother reburied. 2011. The witness. 9 May. [Online]. http://witness.co.za/index.php?show (3 June 2013). 